\title{
Intrinsic Bioactivity of Thyrotropin in Human Serum Is Inversely Correlated with Thyroid Hormone Concentrations

\author{
Application of a New Bioassay Using the FRTL-5 Rat Thyroid Cell Strain
}

Per A. Dahlberg, Patricia A. Petrick, Marina Nissim, M. Margarida Menezes-Ferreira, and Bruce D. Weintraub

Molecular, Cellular, and Nutritional Endocrinology Branch, National Institute of Arthritis, Diabetes,

and Digestive and Kidney Diseases, National Institutes of Health, Bethesda, Maryland 20892

\begin{abstract}
We have developed a new bioassay for thyrotropin (TSH) in human serum to evaluate bioactivity in normal individuals and patients with different degrees of primary hypothyroidism. Unpurified TSH in serum showed no stimulation of cyclic AMP production in cultured FRTL-5 rat thyroid cells, but after immunopurification showed potent stimulatory activity. Immunoaffinity purification permitted up to $\mathbf{4 0 0}$-fold concentration of serum TSH, allowing bioactivity measurements even in certain normal sera. The limit of detection in the FRTL-5 bioassay was $10 \mu \mathrm{U}$ of human TSH per $0.5 \mathrm{ml}$ incubate, and half-maximal responses for standard human TSH was $102 \pm 26( \pm \mathrm{SE}) \mu \mathrm{U} /$ $0.5 \mathrm{ml}$. Immunoaffinity-purified serum TSH varied in bioactivityto-immunoactivity (B/I) ratios from $<0.25$ to 1.21 among four euthyroid subjects and eight primary hypothyroid patients. An inverse correlation was found between $B / I$ ratios of immunopurified basal TSH and the serum-free T4 $(r=-0.7237, P$ $<0.01)$, T4 $(r=-0.6650, P<0.05)$, and T3 $(r=-0.6382, P$ $<0.05)$. B/I ratios of immunopurified TSH from three hypothyroid patients before and after acute stimulation by thyrotropinreleasing hormone showed no significant change, despite major changes in serum TSH. In summary, the present study shows an inverse relationship between the metabolic status of an individual and the intrinsic bioactivity of TSH.
\end{abstract}

\section{Introduction}

The development of radioimmunoassay methods for measurement of human thyrotropin (TSH) ${ }^{1}$ has permitted determination of serum concentrations in various physiologic and pathophysiologic conditions $(1,2)$. Unfortunately, there have only been a few reports comparing TSH bioactivity (B) to its immunoactivity (I). Early in vivo TSH bioassays in rodents were of limited sensitivity and precision, and were affected by possible variations of metabolic clearance rate in the animal (3). Because of these limitations such bioassays were only applied to the measurement of very high TSH concentrations in certain patients with primary hypothyroidism, and yielded highly variable results $(4,5)$.

Address correspondence and reprint requests to Dr. Bruce Weintraub, National Institutes of Health, Building 10, Room 8D14, Bethesda, MD 20892.

Received for publication 14 February 1986 and in revised form 15 December 1986.

1. Abbreviations used in this paper: $\mathrm{B} / \mathrm{I}$, bioactivity-to-immunoactivity ratio; LH, luteinizing hormone; 2nd IRP, Second International Reference Preparation; NIADDK, National Institute of Arthritis, Diabetes, and Digestive and Kidney Diseases; TRH, thyrotropin-releasing hormone; TSH, thyrotropin.

The Journal of Clinical Investigation, Inc.

Volume 79, May 1987, 1388-1394
The development of a sensitive cytochemical method has permitted estimation of TSH bioactivity in small volumes of unfractionated serum from normal individuals as well as from those with primary and central hypothyroidism (6-8). However, the cytochemical bioassay is technically difficult and has only been employed by a few groups. Moreover, the dose-response curves show a shallow slope with a low index of precision (3). Finally, it has not yet been established that this assay, like earlier bioassays employing unfractionated serum, is free from interference by non-TSH stimulators or inhibitors, such as thyroidstimulating and thyroid-inhibiting immunoglobulins (9).

We have previously reported immunoaffinity techniques that permitted purification and concentration of TSH from human serum (10). Such purification has been applied previously to a bioassay method employing stimulation of adenylate cyclase activity in human thyroid membranes (11-13). Using these methods we have shown that one euthyroid patient with a TSH of high molecular weight and seven patients with hypothalamic hypothyroidism had decreased thyrotropic bioactivity and that one patient with a TSH-secreting pituitary tumor had increased thyrotropic bioactivity when compared with patients with primary hypothyroidism (11-13). However, human thyroid membranes are not readily available, and different preparations show widely variable dose-response characteristics.

Recently a clonal line derived from functional rat thyroid cells (FRTL-5) has been widely applied to the measurement of thyroid-stimulating and/or growth-promoting immunoglobulins in human serum $(14,15)$. Although these cells have been used for the bioassay of different pituitary TSH preparations (16), they have not previously been employed for the measurement of TSH bioactivity in animal or human serum.

In the present study we describe a method for the bioassay of TSH immunopurified from the serum of normal individuals and patients with different degrees of primary hypothyroidism. Because of the sensitivity and precision of this new bioassay, we have been able to show a highly significant inverse relationship between serum thyroid hormone concentrations and the intrinsic bioactivity of TSH, and a direct relationship between the serum TSH concentrations and its bioactivity.

\section{Methods}

Subjects. Four normal individuals and eight patients were included in the study. The selection of subjects was based on the availability of relatively large amounts of serum $(15-250 \mathrm{ml})$ necessary for the investigations, and on their metabolic status to represent euthyroidism and different degrees of primary hypothyroidism. Clinical and laboratory data for all patients are presented in Table I. Diagnoses were based on clinical status, thyroid hormone and TSH measurements, thyroid autoantibody titers and, in certain patients, fine-needle aspiration biopsy results and 24-h radioiodine uptake values. In three of the patients with primary hypothyroidism (numbers $6,9,12)$, serum $(5-30 \mathrm{ml}$ ) was also 
Table I. Results of Thyroid Function and TSH B/I Ratios in Four Euthyroid Subjects and Eight Patients with Different Degrees of Primary Hypothyroidism

\begin{tabular}{|c|c|c|c|c|c|c|c|}
\hline $\begin{array}{l}\text { Patient } \\
\text { No. }\end{array}$ & Age/Sex & Diagnosis & FT4 & $\mathrm{T} 4$ & $\mathrm{~T} 3$ & TSH & B/I \\
\hline & & & $n g / d l$ & $\mu g / d l$ & $n g / d l$ & $\mu U / m l$ & mean $\pm S D$ \\
\hline 1 & $30 / \mathrm{M}$ & Normal & 2.1 & 8.5 & 190 & 2.5 & $0.28 \pm 0.04$ \\
\hline 2 & $30 / \mathrm{F}$ & Normal & 1.9 & 9.7 & 143 & 3.5 & $0.30 \pm 0.06$ \\
\hline 3 & $46 / F$ & Normal & 1.9 & 7.4 & 132 & 6 & $<0.25$ \\
\hline 4 & $18 / \mathrm{F}$ & Normal & 1.5 & 6.0 & 130 & 6 & $<0.25$ \\
\hline 5 & $19 / \mathrm{F}$ & $\begin{array}{l}\text { Subclinical hypothyroidism } \\
\text { (Hashimoto's disease) }\end{array}$ & 1.2 & 6.9 & 133 & 14 & $0.25 \pm 0.08$ \\
\hline 6 & $36 / F$ & $\begin{array}{l}\text { Primary hypothyroidism } \\
\text { (Hashimoto's disease) }\end{array}$ & 1.0 & 4.2 & 110 & 50 & $0.65 \pm 0.10$ \\
\hline 7 & $57 / F$ & $\begin{array}{r}\text { Primary hypothyroidism } \\
\text { (Hashimoto's disease) }\end{array}$ & 1.0 & 2.1 & 130 & 147 & $0.47 \pm 0.10$ \\
\hline 8 & $23 / F$ & $\begin{array}{l}\text { Primary hypothyroidism } \\
\text { (Hashimoto's disease) }\end{array}$ & 0.8 & 3.4 & 90 & 198 & $0.66 \pm 0.16$ \\
\hline 9 & $45 / F$ & $\begin{array}{l}\text { Primary hypothyroidism } \\
\text { (Post 131-I therapy for Graves' disease) }\end{array}$ & 0.6 & 3.2 & 109 & 410 & $1.21 \pm 0.33$ \\
\hline 10 & $50 / \mathrm{F}$ & $\begin{array}{l}\text { Primary hypothyroidism } \\
\text { (Hashimoto's disease) }\end{array}$ & 0.6 & 4.0 & 113 & 108 & $0.34 \pm 0.11$ \\
\hline 11 & $69 / \mathrm{F}$ & $\begin{array}{l}\text { Primary hypothyroidism } \\
\text { (Postoperative thyroid carcinoma) }\end{array}$ & 0.4 & 4.0 & 94 & 93 & $0.83 \pm 0.23$ \\
\hline 12 & $25 / \mathrm{F}$ & $\begin{array}{r}\text { Primary hypothyroidism } \\
\text { (Hashimoto's disease) }\end{array}$ & 0.2 & 0.6 & 77 & 400 & $0.81 \pm 0.10$ \\
\hline
\end{tabular}

Normal range

obtained at $20,45,60,120$, and $180 \mathrm{~min}$ after the injection of $500 \mu \mathrm{g}$ thyrotropin-releasing hormone (TRH) as presented in Table II.

Assays of serum hormones. Radioimmunoassays of thyroxine (T4) and triiodothyronine (T3) were performed by commercial kits (Corning Laboratories, Corning, NY). Free thyroxine $\left(\mathrm{FT}_{4}\right)$ was performed by a dialysis method at SmithKline Bio-Science Laboratories, Sunnyvale, CA. TSH was measured by a previously published double-antibody radioimmunoassay method $(17,18)$. The respective normal values for the various assays are shown in Table I. For the TSH assay the sensitivity was 0.8 $\mu \mathrm{U} / \mathrm{ml}$ using $0.2 \mathrm{ml}$ of serum, and the World Health Organization (WHO) Second International Reference Preparation (2nd IRP) of TSH (80/558) was usechas a standard (19). Each TSH sample was assayed in duplicate

Table II. Serum TSH Levels and B/I Ratios Before and At Various Intervals After an Acute Injection of $500 \mu \mathrm{g} T R H$ in Three Patients with Primary Hypothyroidism

\begin{tabular}{lllll}
\hline & $0 \mathrm{~min}$ & $20 \mathrm{~min}$ & $\begin{array}{l}45+60 \mathrm{~min} \\
(\mathrm{pool})\end{array}$ & $\begin{array}{l}120+180 \mathrm{~min} \\
(\mathrm{pool})\end{array}$ \\
\hline $\begin{array}{l}\text { Patient No. } 6 \\
\text { TSH }\end{array}$ & $50^{*}$ & 211 & 171 & 87 \\
$\begin{array}{c}\text { B/I } \\
\text { Patient No. } 12\end{array}$ & $0.65 \pm 0.10^{\ddagger}$ & $0.70 \pm 0.20$ & $0.44 \pm 0.03$ & $0.46 \pm 0.04$ \\
$\quad$ TSH & 400 & 927 & 1047 & 718 \\
$\begin{array}{l}\text { B/I } \\
\text { Patient No. } 9\end{array}$ & $0.81 \pm 0.10$ & $0.84 \pm 0.14$ & $0.70 \pm 0.15$ & $0.77 \pm 0.07$ \\
$\begin{array}{l}\text { TSH } \\
\text { B/I }\end{array}$ & 410 & 778 & - & - \\
& $1.21 \pm 0.33$ & $1.55 \pm 0.25$ & - & - \\
\hline
\end{tabular}

$* \mu \mathrm{mU} / \mathrm{ml}$

${ }^{\ddagger}$ Mean \pm SD of 3-4 determinations. at three to four dilutions and the results were calculated using a fourparameter sigmoidal program (20).

Immunopurification of serum TSH. Partial purification of serum TSH was performed by immunoaffinity chromatography on an anti- $\alpha$ column as previously described (10). Serum $(15-250 \mathrm{ml})$ was centrifuged at $102,000 \mathrm{~g}$ for $1 \mathrm{~h}$ at $4^{\circ} \mathrm{C}$, and was applied to the column overnight at $4^{\circ} \mathrm{C}$. TSH was eluted with $3.0 \mathrm{M}$ guanidine- $\mathrm{HCl}, \mathrm{pH} 3.2$. The eluates were directly transferred into dialysis bags (PA-10; Bio-Molecular Dynamics, Beaverton, OR) and extensively dialyzed against hypotonic Hanks' balanced salt solution (HBSS). The samples were then concentrated to a final volume of $0.5-1 \mathrm{ml}$ by vacuum dialysis (Micro-ProDiCon dialysis/concentrator unit; Bio-Molecular Dynamics) against the same buffer and stored at $-20^{\circ} \mathrm{C}$ up to $2 \mathrm{wk}$ before being tested for bioactivity. Between experiments, any residual tightly bound material was eluted with $6.0 \mathrm{M}$ guanidine- $\mathrm{HCl}, \mathrm{pH} 3.2$. The TSH binding capacity per milliliter of antibody-coupled agarose was $6,000 \mu \mathrm{U}$ of TSH in terms of the 2nd IRP, which was equivalent to $0.53 \mu \mathrm{g}$ of purified TSH (CalbiochemBehring Corp., La Jolla, CA) or $4.0 \mu \mathrm{g}$ of crude TSH (National Institute of Arthritis, Diabetes, and Digestive and Kidney Diseases [NIADDK] Hormone Distribution Program Reference Preparation 1). During purification and concentration of serum samples, $40-60 \%$ of the original immunoreactive TSH was recovered. Of the TSH lost, 10-30\% was in the fraction not bound to the column, $5-15 \%$ in the $6 \mathrm{M}$ guanidine wash and $10-30 \%$ in the subsequent handling of the $3 \mathrm{M}$ guanidine eluate. There were no systematic differences in the proportions of immunoreactive TSH recovered at various purification steps among the various patient groups. The current method of concentration of eluted TSH was more convenient than the lyophilization (11-13), and yielded the same recovery of the original material as the latter without affecting bioactivity. The TSH in the $6 \mathrm{M}$ guanidine eluates that were tested for bioactivity was handled as described for $3 \mathrm{M}$ guanidine eluates, whereas the TSH in the fractions not bound to the column was lyophilized, reconstituted in hypotonic HBSS, and dialyzed against the same buffer before bioassay. The possibility of antibody leakage in eluates or dissociation of TSH 
into its $\alpha$ and $\beta$ subunits during purification was ruled out as previously described (12).

TSH bioassay. The FRTL-5 rat thyroid cell strain was kindly provided by Dr. L. D. Kohn and Dr. C. Rotella (NIADDK). Details of the derivation and characteristics of this clonal line of functional rat thyroid epithelial cells have been described in previous reports $(21,22)$. Cells were maintained in Coon's modified Ham's F12 medium containing 5\% calf serum (Gibco, Grand Island, NY), $100 \mathrm{U} / \mathrm{ml}$ penicillin, and 100 $\mu \mathrm{g} / \mathrm{ml}$ streptomycin and a supplement of six hormones $(6 \mathrm{H})$ consisting of $10 \mathrm{mU} / \mathrm{ml}$ bovine TSH (Armour Pharmaceutical Co., Tarrytown, $\mathrm{NY}$ ); $10 \mu \mathrm{g} / \mathrm{ml}$ bovine insulin (Sigma Chemical Co., St. Louis, MO); $10^{-8} \mathrm{M}$ hydrocortisone (Sigma Chemical Co.); $5 \mu \mathrm{g} / \mathrm{ml}$ transferrin (Sigma Chemical Co.); $10 \mathrm{ng} / \mathrm{ml}$ glycyl-L-histidyl lysine acetate, (Sigma Chemical Co.); and $10 \mathrm{ng} / \mathrm{ml}$ somatostatin (Calbiochem-Behring Corp.). Cells were detached, plated, and grown by established techniques $(21,22)$. The bioassay procedure used is a modification of previously described methods (23-25). Cells to be utilized for bioassay were split from confluent 10$\mathrm{cm}$ Petri dishes, suspended as individual cells in $6 \mathrm{H}$ media, and seeded at a density of $1-2 \times 10^{5} \mathrm{cells} / \mathrm{ml}$ in 24-well tissue culture plates. Media was changed every $3 \mathrm{~d}$, and when confluent the cells were switched to the same medium without TSH $(5 \mathrm{H})$. After $7-10 \mathrm{~d}$ the cells were washed with isotonic HBSS, and the assay was then performed by incubating the cells with TSH diluted in $0.5 \mathrm{ml}$ of hypotonic HBSS $(5 \mathrm{mM} \mathrm{KCl}$, $1.3 \mathrm{mM} \mathrm{CaCl}_{2}, 0.4 \mathrm{mM} \mathrm{MgSO}_{4}, 0.34 \mathrm{mM} \mathrm{Na}_{2} \mathrm{HPO}_{4}, 0.44 \mathrm{mM} \mathrm{KH}_{2} \mathrm{PO}_{4}$, and $0.1 \%$ glucose; $\mathrm{pH} 7.4$ ) containing $0.04 \%$ bovine serum albumin (BSA) and $0.05 \mathrm{mM}$ 3-isobutyl-1-methylxanthine. Several reference preparations of TSH were tested, including crude bovine TSH (Armour Pharmaceutical Co.), purified human TSH (Calbiochem-Behring Corp.) and crude human TSH (WHO 2nd IRP; kindly supplied by Dr. A. F. Bristow, London). TSH samples were diluted in the incubation medium and assayed in duplicate or triplicate at each of three to four dilutions. Incubations were continued for $30 \mathrm{~min}$ at $37^{\circ} \mathrm{C}$ in $5 \% \mathrm{CO}_{2} / 95 \%$ air-humidified atmosphere, then the media was removed and immediately frozen at $-20^{\circ} \mathrm{C}$. Extracellular cyclic AMP (cAMP) was measured by radioimmunoassay after acetylation in $0.05 \mathrm{M} \mathrm{Na}$ acetate buffer, pH $6.2(26,27)$, employing cAMP antiserum purchased from Becton-Dickinson \& Co., Orangeburg, NY. The radioligand $\left[{ }^{125} \mathrm{I}\right] \mathrm{cAMP}$ was obtained from Meloy Laboratories, Bethesda, MD. Results were expressed as fmol of cAMP per well.

TSH bioactivity was determined as the cAMP production in stimulated FRTL-5 cells. The detection limit of the assay was $10 \mu \mathrm{U} /$ well of hTSH WHO 2nd IRP, and the intra-assay coefficient of variation was 9\%. Dose-response curves of the different reference preparations were analyzed with the four-parameter logistic model suggested by De Lean et al. (20), allowing comparisons of biopotency and parallelism. The individual bioactivity of the immunoaffinity-purified samples was evaluated using the 2nd IRP as the internal standard and calculated from the four-parameter logistic equation:

$y=\frac{a-d}{1+(x / c)^{b}}+d$

where $y$ is the response, $x$ is the arithmetic dose, $a$ is the response when $x=0, d$ is the response for "infinite" dose, $c$ is the $\mathrm{FD}_{50}$, and $b$ is the "slope factor." Data were expressed as biologic to immunologic ratios, and a value of 1 was assigned to the bioactivity-to-immunoactivity (B/I) ratio for the 2nd IRP. It should be noted that this standard is different from that used in prior reports of TSH bioactivity from our laboratory (11-13), accounting for differences in the absolute B/I of hypothyroid serum in this compared with previous reports.

Validation of methods. A variety of control experiments were performed to rule out possible bioassay artifacts related to selectivity in immunoaffinity purification or to unknown inhibitors or non-TSH stimulatory factors present in serum: $(a)$ When constant concentrations of standard human TSH (Calbiochem-Behring Corp.) diluted in 5, 50, and $200 \mathrm{ml}$ of phosphate-buffered saline $(10 \mathrm{mM}$ sodium phosphate $+150 \mathrm{mM}$ sodium chloride), $\mathrm{pH} 7.4$, containing $0.02 \%$ sodium azide and $0.1 \%$ BSA, were immunoaffinity purified, no differences in recovery were found among the $3 \mathrm{vol}$, the recovery being $\sim 75 \%$ for all. (b) No differences in recovery were found when different concentrations of standard human TSH (Calbiochem-Behring Corp.) ranging from 200 to $2,000 \mu \mathrm{U} / \mathrm{ml}$ diluted in constant volumes of TSH-free human serum (unbound fraction of immunoaffinity-purified serum from normal subjects) were immunoaffinity purified. (c) When the same serum sample obtained from one single plasmapheresis was immunoaffinity purified in two separate occasions, the recovery ranged between 40 and $60 \%$, whereas the bioactivity was the same with no evidence of selective recovery of high vs. low B/I TSH. (d) When human TSH (CalbiochemBehring Corp.) was immunoaffinity purified, dialyzed, and subsequently handled exactly as the patients' samples, we did not find any significant change in its bioactivity when compared with the nonimmunoaffinitypurified standard. (e) The presence of unknown inhibitory or non-TSH stimulatory factors in immunoaffinity-purified serum TSH was ruled out on the basis of the following mixing experiment. Similar amounts of TSH samples from patients with low and high B/I ratios were mixed with both high and low amounts of standard human TSH (CalbiochemBehring Corp.). No modification of standard TSH bioactivity was detected other than the one predicted (i.e., the TSH standard activity was additive with the endogenous TSH activity).

Statistics. Pearson's correlation coefficient was calculated between the TSH B/I and serum values for FT4, T4, T3, and TSH measured by radioimmunoassay. The TSH dose-response curves for radioimmunoassay were linearized using a logit-log transformation, and the parallelism of curves was tested with Student's $t$ test.

\section{Results}

The typical dose-response curves of the FRTL-5 bioassay to nonimmunoaffinity-purified bovine and human TSH pituitary preparations, obtained using a four-parameter logistic model are shown in Fig. 1. The biopotencies of the tested preparations were similar, with half-maximal responses $\left(E_{50}\right)$ for crude human TSH (2nd IRP)-purified human TSH, and crude bovine TSH being $102 \pm 26 \mu \mathrm{U} / 0.5 \mathrm{ml}( \pm \mathrm{SE}), 106 \pm 30 \mu \mathrm{U} / 0.5 \mathrm{ml}$, and $131 \pm 41 \mu \mathrm{U} / 0.5 \mathrm{ml}$, respectively. These values were not statistically different.

Cross-reactivity in the bioassay was tested for the following hormones and subunits: hTSH $\alpha$-subunit, $50-1,000 \mathrm{ng}$ (NIADDK, hTSH $\alpha$-1); hTSH $\beta$-subunit, 50-2,000 ng (NIADDK, hTSH $\beta$-2); hLH, 50-1,000 ng (NIADDK, hLH-I3); hFSH, 50-1,000 ng (NIADDK, hFSH-I-6); hCG $\alpha$-subunit, 50-1,000 ng (NICHD and NIADDK, hCG $\alpha$-CR-1 19); and hCG $\beta$-subunit, 50-1,000 ng (NICHD and NIADDK, hCG $\beta$-CR123). No stimulation of cAMP was demonstrated other than that attributable to known TSH contamination of the hLH I-3 (40 $\mu \mathrm{U} / \mu \mathrm{g})$ and $\mathrm{hFSH} \mathrm{I}-6(120 \mu \mathrm{U} / \mu \mathrm{g})$ preparations. TRH, tested in the dose range of $10^{-12} \mathrm{M}$ to $10^{-6} \mathrm{M}$, showed no intrinsic stimulation in this assay.

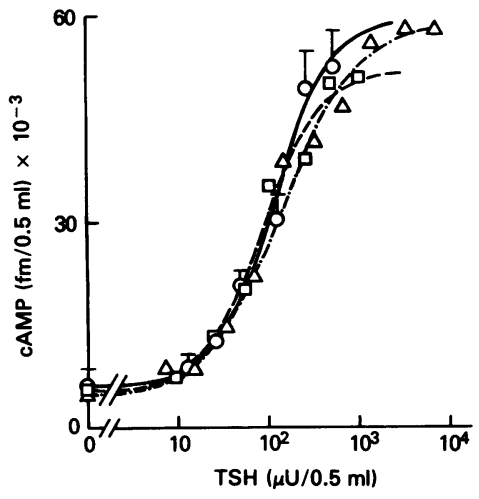

Figure 1. TSH bioassay in FRTL-5 cells. Dose-response curves of bTSH Armour (-- --$)$, hTSH Calbiochem $(\cdot \cdot-\Delta \cdot \cdot-)$, and hTSH WHO 2nd IRP $(-0-)$ reference preparations using the four parameter logistic model. +1SD is shown only for hTSH WHO 2nd IRP used as internal standard, but SDs for the other preparations were similar. 
Unpurified samples of serum TSH showed no stimulation of cAMP in the FRTL-5 bioassay even after dialysis against the hypotonic assay buffer. When increasing amounts of dialyzed serum from normal and primary hypothyroid patients were added to known quantities of immunoaffinity-purified hTSH, there was a progressive decrease in cAMP production at each TSH concentration of the immunopurified standard (data not shown). The inhibition was $\sim 60 \%$ when $10 \%$ of dialyzed serum was present in the incubation medium and $>80 \%$ in the presence of $40 \%$ dialyzed serum. No significant differences were detected between normal and primary hypothyroid serum. The inhibitory factors were not affected by preabsorption of the serum with staphylococcal protein A coupled to Sepharose, indicating that they were not IgG of the major subclasses 1, 2, 4. Further characterization of the serum inhibitors was not attempted, because a previous report (28) showed that they were heterogeneous and present in the macroglobulin, gamma globulin, and albumin components of serum.

After TSH was immunoaffinity-purified from serum, it showed a potent stimulatory activity. The dose-response curves of immunoreactive serum TSH, obtained from one of the patients with primary hypothyroidism (No. 12) before (12b) and after (12a) immunopurification, are depicted in Fig. $2 A$. In Fig. $2 B$, additional dose-response curves of representative immunoaffinity purified samples are shown. Two hypothyroid patients demonstrating potent stimulatory activity (Nos. 8 and 9), one subclinical hypothyroid patient demonstrating weak stimulatory activity (No. 5), and one euthyroid control demonstrating no stimulatory activity above the limit of detection (No. 4) are illustrated. All immunoaffinity-purified samples with significant stimulatory activity showed a parallelism to the 2nd IRP reference preparation that was used as standard in our FRTL-5 bioassay.

In four patients (Nos. 7, 9, 10, 12) the bioactivity was also tested for the TSH that did not bind to the column during immunopurification, as well as for the TSH that appeared in the $6 \mathrm{M}$ wash fraction. No stimulation of cAMP was seen in either of these fractions (data not shown). The unbound TSH produced a cAMP response lower than the baseline, most likely related to serum inhibitory factors, as described by Rapoport and Adams (28), whereas the lack of stimulation by the fraction eluted with $6 \mathrm{M}$ guanidine could be accounted for by either a tightly bound form of TSH with low activity and/or denaturation of the TSH molecule at high salt concentration. We have previously shown no irreversible denaturation effects of brief exposure to guanidine at concentrations below $3 \mathrm{M}$ at $4^{\circ} \mathrm{C}(10)$.

$\mathrm{TSH}$, which bound to the immunoaffinity column during purification and eluted with brief exposure to $3 \mathrm{M}$ guanidine, varied in $\mathrm{B} / \mathrm{I}$ ratios from $<0.25$ to 1.21 among four euthyroid subjects and eight mildly to severely hypothyroid patients (Table I). An inverse correlation was found between the B/I ratios of immunopurified basal TSH and the serum FT4 $(r=-0.7237$; $P<0.01)$, T4 ( $r=-0.6650 ; P<0.05)$, and T3 $(r=-0.6382$; $P<0.05$ ) concentrations, in all measured samples (Fig. 3, $A-$ $C)$. Moreover, a direct correlation was found between the $\mathrm{B} / \mathrm{I}$ ratios of immunopurified TSH and the serum TSH $(r=0.8355$; $P<0.001$ ) concentration (Fig. $3 D$ ). For the statistical evaluation of the respective correlation coefficients, all $\mathrm{B} / \mathrm{I}$ ratios of $<0.25$ were given the value of 0.25 . If a $\mathrm{B} / \mathrm{I}$ value of 0.125 or 0.0 was given instead, the correlations obtained did not change significantly ( $r$ for FT4 from -0.7237 to -0.7384 and -0.7406 ; $r$ for T4 from -0.6650 to -0.6615 and $-0.6491 ; r$ for T3 from -0.6382 to -0.6170 and $-0.5901 ; r$ for TSH from 0.8355 to 0.8300 and 0.8135 , respectively).

In three hypothyroid patients B/I ratios of immunopurified TSH were evaluated in samples obtained before and after acute stimulation by TRH (Table II). The B/I ratio of the released material did not significantly differ from that of basal TSH, despite major changes in serum TSH concentration. This clearly indicates the consistency of TSH B/I ratios in a given patient, thus ruling out that different $\mathrm{B} / \mathrm{I}$ ratios were related to assay artifacts such as increased stability of TSH at higher concentrations.

In the radioimmunoassay, linearized TSH dose-response curves from nonimmunopurified hTSH Calbiochem reference preparation and from euthyroid and hypothyroid subjects before and after purification did not differ significantly from those of the 2nd IRP used as a standard when tested for parallelism (Table III).

\section{Discussion}

In the present study we have compared the B/I ratios of circulating TSH obtained after immunoaffinity purification of serum from euthyroid, mildly hypothyroid, and severely hypothyroid subjects. We then correlated these ratios to the serum levels of both TSH and thyroid hormones in each subject. The B/I ratios
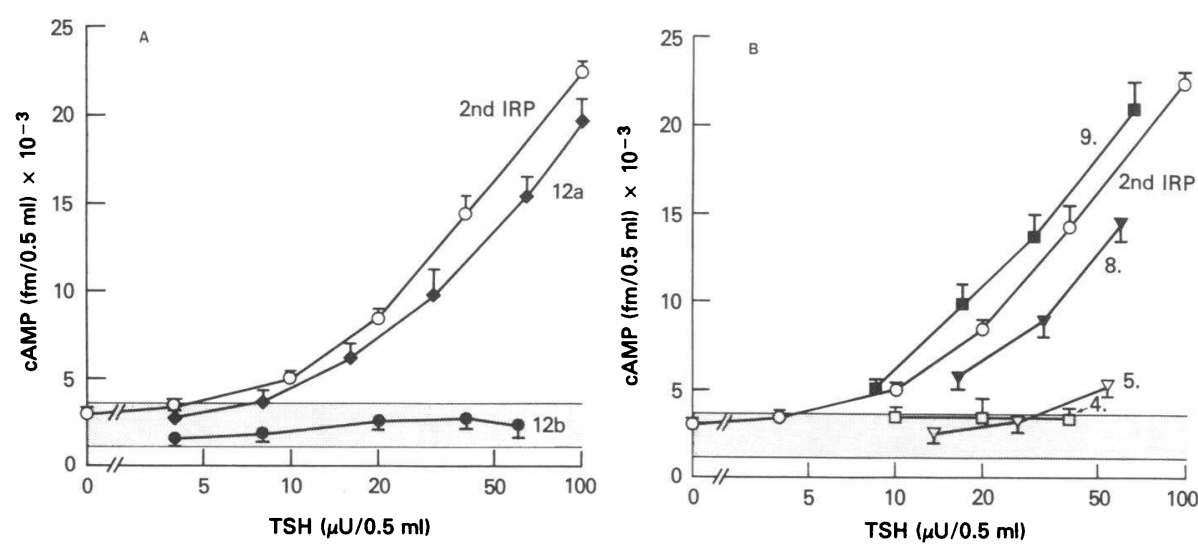

Figure 2. (A) Dose-response curves of TSH from serum after immunopurification $(12 \mathrm{a},-\bullet-)$ and from unpurified serum dialyzed against hypotonic assay buffer $(12 \mathrm{~b},-\bullet-)$ from the same patient with primary hypothyroidism (No. 12) in relation to standard hTSH (- $\mathrm{O}-$ ). For the unpurified sample, 4$60 \mu \mathrm{U}$ TSH corresponds to $0.01-0.15 \mathrm{ml}$ (2-30\%) serum per 0.5-ml well. (B) Doseresponse curves of TSH after immunopurification from two patients with primary hypothyroidism (No. 8, - - , and No. 9, — -), from one patient with subclinical hypothyroidism (No. $5,-\nabla-$ ), and from one normal (No. 4, - $\longrightarrow$ ) in relation to standard $\mathrm{hTSH}$. 

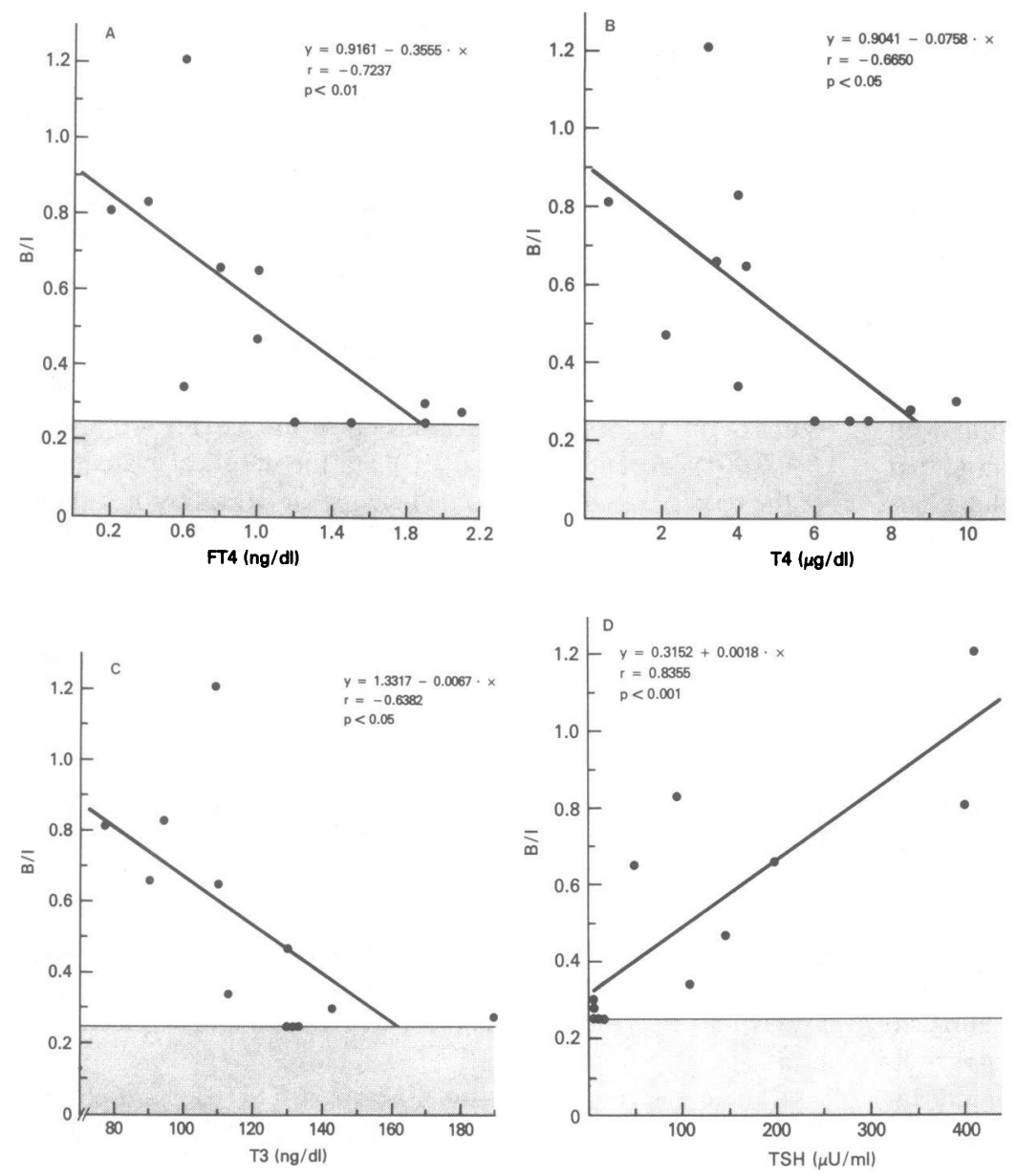

Figure 3. Relationship between B/I ratios of immunopurified TSH evaluated in the FRTL-5 bioassay and basal serum levels of FT4 $(A)$, T4 $(B)$, T3 $(C)$, and TSH $(D)$ measured by radioimmunoassay.

correlated directly with serum basal values of TSH $(P<0.001)$ and inversely with FT4 $(P<0.01)$, T4 $(P<0.05)$, and T3 $(P$ $<0.05)$, thereby indicating an inverse relationship between the metabolic status of an individual and the quality of circulating TSH. The existence of a significant correlation between the bioactivity of a pituitary hormone and its target organ's serum hormone concentration has not previously been described. The results are, however, generally in agreement with findings concerning other pituitary glycoprotein hormones, because increased in vitro bioactivity for luteinizing hormone (LH) has been re-

Table III. Statistical Comparison of TSH Radioimmunoassay Logit-Log Slopes before and after Immunoaffinity

Purification Compared with WHO 2nd IRP Used a Standard

Nonimmunopurified WHO 2nd IRP hTSH standard (9)

$-1.047 \pm 0.118$

Nonimmunopurified hTSH Calbiochem reference prep (3)

$-0.998 \pm 0.082$

Nonimmunopurified serum samples from normals and hypothyroid patients (12)

$-1.022 \pm 0.104$

Immunopurified samples from normals (4)

Immunopurified samples from hypothyroid patients (8)

$-0.990 \pm 0.100$

$-1.024 \pm 0.116$

The number of estimations are in parentheses. Values are the mean \pm 2 SD. No significant differences between the respective groups were observed. ported in postmenopausal compared with premenopausal women (29) and this increased bioactivity can be reduced by estrogen therapy (30).

Other than our previous studies (11-13), the only reports concerning TSH bioactivity and $\mathrm{B} / \mathrm{I}$ ratios in normal or diseased humans used the cAMP activation assay in primary cultures of dog thyroid cells (28) and the cytochemical assay (6-8). The results of the cytochemical assay system are difficult to compare with our present study because it employs unfractionated serum, is subject to other technical problems, and uses different reference standards. Rapoport and Adams, using the cAMP activation assay in dog thyroid cells, used only gel filtration to purify TSH, did not evaluate TSH B/I ratios, and found undetectable TSH bioactivity in normal subjects. We have previously published three reports concerning the B/I ratios of affinity-purified TSH in human serum, using a bioassay system involving stimulation of adenylate cyclase in thyroid membranes (11-13). In all these studies, different TSH reference standards with different biopotencies were used to determine B and I. Thus, comparison of the absolute B/I ratios in these and the present study are not possible. Moreover, the controls employed in our previous studies primarily consisted of patients with severe primary hypothyroidism, and there was no investigation of normal subjects or patients with mild primary hypothyroidism.

Thyroid hormones exert a powerful negative feedback control over TSH synthesis and release, acting at pituitary and possibly hypothalamic levels. Besides the long-recognized direct pituitary action of thyroid hormones on the suppression of basal and 
TRH-stimulated TSH secretion (31), it has recently been demonstrated that thyroid hormones also act at a pretranslational level by direct inhibition of the transcription of TSH $\alpha$ - and $\beta$ subunit genes $(32,33)$. Although thyroid hormone action at the hypothalamic level is not yet defined, there is evidence to suggest an additional negative feedback role upon TRH synthesis and release (34). We have previously shown that different forms of TSH with different lectin-binding properties and presumably different carbohydrate compositions show widely different bioactivities; certain of these forms act as competitive antagonists of more bioactive TSH (35). We have also demonstrated that chemical deglycosylation of TSH greatly reduces its bioactivity and produces a form that acts as a competitive antagonist (36). Since thyroid hormones have been shown to affect TSH glycosylation in rodents $(37,38)$, our present study suggests that they may also affect posttranslational TSH carbohydrate processing in man, either by a direct effect on the thyrotrophs or indirectly through TRH release and secretion.

The metabolic clearance rate of human FSH derived from postmenopausal women was found to be lower than that of FSH obtained from premenopausal women (39). Similarly, the TSH derived from hypothyroid rats has also been shown to have a lower clearance rate than that derived from normal rats (40). There may, therefore, be selective peripheral metabolism of certain circulating forms of TSH to preserve biologically active TSH forms in the circulation of hypothyroid subjects. This hypothesis is supported by data showing that TSH secreted from pituitaries of hypothyroid rats in vitro has a similar bioactivity to that from normal rats (41).

We did not observe any significant change in biopotency of TSH 20-180 min after acute TRH stimulation in three patients with severe primary hypothyroidism. In contrast, acute TRH stimulation in patients with central hypothyroidism appeared to release somewhat more bioactive TSH forms, an effect more obvious after chronic TRH stimulation (12). It is reasonable to assume that primary hypothyroid patients already are subjected to a chronic TRH stimulation via physiological feedback mechanism and therefore cannot respond to further stimulation. In central hypothyroidism with presumable TRH deficiency, an acute TRH injection probably releases prestored TSH forms of higher biopotency but chronic TRH stimulation may be required to significantly induce the formation of more bioactive TSH. In animal experiments it has, moreover, been shown that TRH regulation of TSH glycosylation is a time-dependent event, appearing at $\sim 6 \mathrm{~h}$ in hypothyroid rats and at $24 \mathrm{~h}$ in euthyroid animals (42).

A change in $\mathrm{B} / \mathrm{I}$ ratios during different physiological or pathophysiological conditions could logically reflect changes in either B or I. Although usually reflective of changes in B, a change in I was recently demonstrated for certain forms of $\mathrm{LH}$, which were nonparallel to the standard $\mathrm{LH}$ in radioimmunoassay (43). However, in the current investigation the parallel slopes noted in our TSH radioimmunoassay for different dilutions of unpurified and purified samples from euthyroid and hypothyroid subjects, as well as for nonimmunopurified human TSH Calbiochem reference preparation, suggest a "true" change in bioactivity. It has, moreover, been demonstrated that purified TSH does not show any change in I after deglycosylation, in spite of major changes in B (36). Therefore, it appears that the polyclonal antiserum used in our current TSH radioimmunoassay is unlikely to be sensitive to changes in carbohydrate content that may account for changes in TSH bioactivity. Be- cause immunopurified serum TSH is still quite impure, there are no other methods available to measure TSH concentrations other than immunoassay.

In summary, the present investigation shows an inverse relationship between the metabolic status of an individual in terms of circulating thyroid hormone levels and the biological potency of the circulating TSH. Because of the known relationship between TSH bioactivity and glycosylation, as well as the evidence for thyroid hormone regulation of TSH glycosylation and metabolic clearance, it seems likely that our observed variation in TSH bioactivity results from thyroid hormone regulated alterations in TSH carbohydrate structure. Such alterations may occur during TSH synthesis, secretion, or peripheral metabolism. Thus, the modulation of TSH carbohydrate structure may provide the basis for regulation of hormone action in various physiologic states.

\section{Acknowledgments}

We thank Dr. Vincenzo Guardabasso for his valuable contribution with the statistical evaluations and Dr. Carlo Rotella for his assistance with the FRTL-5 cells.

This study was supported by grants from the Swedish Medical Research Council (No. 7040), Henning and Johan Throne-Holst's Foundation, and Anders Otto Swärd's Foundation (for Dr. Dahlberg).

\section{References}

1. Condliffe, P. G., and B. D. Weintraub. 1979. Pituitary thyroidstimulating hormone and other thyroid-stimulating substances. In Hormones in Blood. C. H. Gray and V. H. T. James, editors. Academic Press, London. 1:499-574.

2. Wehmann, R. E., and B. C. Nisula. 1984. Radioimmunoassay of human thyrotropin: analytical and clinical developments. CRC Crit. Rev. Lab. Sci. 20:243-283.

3. Gorden, P., and B. D. Weintraub. 1985. Radioreceptor and other functional hormone assays. In Williams Textbook of Endocrinology. J. D. Wilson and D. W. Foster, editors. W. B. Saunders Co., Philadelphia. 133-146.

4. Miyai, K., M. Fukuchi, and Y. Kumahara. 1969. Correlation between biological and immunological potencies of human serum and pituitary thyrotropin. J. Clin. Endocrinol. 29:1438-1442.

5. Hershman, J. M., and J. A. Pittman. 1971. Utility of the radioimmunoassay of serum thyrotropin in man. Ann. Intern. Med. 74:481490.

6. Petersen, V., B. R. Smith, and R. Hall. 1975. A study of thyroid stimulating activity in human serum with the highly sensitive cytochemical bioassay. J. Clin. Endocrinol. Metab. 41:199-202.

7. Döhler, K.-D., T. Hashimoto, and A. von zur Mühlen. 1978. Use of a cytochemical bioassay for determination of thyroid stimulating hormone in clinical investigation. In Radioimmunoassay and Related Procedures in Medicine. 1977. International Atomic Energy Agency, Vienna, VA. 297-307.

8. Faglia, G., L. Bitensky, A. Pinchera, C. Ferrari, A. Paracchi, P. Beck-Peccoz, B. Ambrosi, and A. Spada. 1979. Thyrotropin secretion in patients with central hypothyroidism: evidence for reduced biological activity of immunoreactive thyrotropin. J. Clin. Endocrinol. Metab. 48: 989-998.

9. Valente, W. A., Z. Yavin, E. Yavin, E. F. Grollman, M. D. Schneider, C. Rotella, R. Zonefrati, R. S. Toccafondi, and L. D. Kohn. 1982. Monoclonal antibodies to the thyrotropin receptor: the identification of blocking and stimulating antibodies. J. Endocrinol. Invest. 5:293-301.

10. Pekonen, F., D. M. Williams, and B. D. Weintraub. 1980. Purification of thyrotropin and other glycoprotein hormones by immunoaffinity chromatography. Endocrinology. 106:1327-1332. 
11. Spitz, I. M., D. Le Roith, H. Hirsch, P. Carayon, F. Pekonen, Y. Liel, R. Sobel, Z. Chorer, and B. D. Weintraub. 1981. Increased highmolecular-weight thyrotropin with impaired biologic activity in a euthyroid man. N. Engl. J. Med. 304:278-282.

12. Beck-Peccoz, P., S. Amr, M. M. Menezes-Ferreira, G. Faglia, and B. D. Weintraub. 1985. Decreased receptor binding of biologically inactive thyrotropin in central hypothyroidism. N. Engl. J. Med. 312: 1085-1090.

13. Beck-Peccoz, P., G. Piscitelli, S. Amr, M. Ballabio, M. Bassetti, G. Giannattasio, A. Spada, M. Nissim, B. D. Weintraub, and G. Faglia. 1986. Endocrine, biochemical and morphological studies of a pituitary adenoma secreting GH, TSH and $\alpha$-subunit: evidence for secretion of TSH with increased bioactivity. J. Clin. Endocrinol. Metab. 62:704-711.

14. Vitti, P., W. A. Valente, F. S. Ambesi-Impiombato, G. F. Fenzi, A. Pinchera, and L. D. Kohn. 1982. Graves' IgG stimulation of continuously cultured rat thyroid cells: a sensitive and potentially useful clinical assay. J. Endocrinol. Invest. 5:179-182.

15. Valente, W. A., P. Vitti, C. M. Rotella, M. M. Vaughan, S. M. Aloj, E. F. Grollman, F. S. Ambesi-Impiombato, and L. D. Kohn. 1983. Antibodies that promote thyroid growth: a distinct population of thyroidstimulating autoantibodies. N. Engl. J. Med. 39:1028-1034.

16. Bidey, S. P., K. Ryder, R. Gaines-Das, N. J. Marshall, and R. P. Ekins. 1984. A comparison of the bioactivity of human and bovine thyrotropin preparations, as determined by intracellular cyclic AMP responses of cultured FRTL-5 cells and human thyroid cell monolayers. Acta Endocrinol. 106:482-489.

17. Ridgway, E. C., B. D. Weintraub, J. L. Cevallos, C. M. Rack, and F. Maloof. 1973. Suppression of pituitary TSH secretion in the patient with a hyperfunctioning thyroid nodule. J. Clin. Invest. 52:2783-2793.

18. Gershengorn, M. C., and B. D. Weintraub. 1975. Thyrotropininduced hyperthyroidism caused by selective pituitary resistance to thyroid hormone. A new syndrome of "inappropriate secretion of TSH". J. Clin. Invest. 56:633-642.

19. Gaines Das, R. E., and A. F. Bristow. 1985. The second international reference preparation of thyroid-stimulating hormone, human, for immunoassay: calibration by bioassay and immunoassay in an international collaborative study. J. Endocrinol. 104:367-379.

20. De Lean, A., P. J. Munson, and D. Rodbard. 1978. Simultaneous analysis of families of sigmoidal curves: application to bioassay, radioligand assay, and physiological dose-response curves. Am. J. Physiol. 235:E97-E102.

21. Ambesi-Impiombato, F. S., L. A. M. Parks, and H. G. Coon. 1980. Culture of hormone-dependent epithelial cells from rat thyroids. Proc. Natl. Acad. Sci. USA. 77:3455-3459.

22. Ambesi-Impiombato, F. S., R. Picone, and D. Tramontano. 1982. The influence of hormones and serum on the growth and differentiation of the thyroid cell strain FRTL. In Growth of Cells in HormonallyDefined Media. G. H. Sato, A. Pardee, and D. A. Sirbasku, editors. Cold Spring Harbor Conference on Cell Proliferation, New York. 9:483-492.

23. Valente, W. A., P. Vitti, L. D. Kohn, M. L. Brandi, C. M. Rotella, R. Toccafondi, D. Tramontano, S. M. Aloj, and F. S. Ambesi-Impiombato. 1983. The relationship of growth and adenylate cyclase activity in cultured thyroid cells: separate bioeffects of thyrotropin. Endocrinology. 112:71-79.

24. Kasagi, K., J. Konishi, Y. Iida, K. Ikekubo, T. Mori, K. Kuma, and $\mathrm{K}$. Torizuka. 1982. A new in vitro assay for human thyroid stimulators using cultured thyroid cells: effect of sodium chloride on adenosine 3'5' monophosphate increase. J. Clin. Endocrinol. Metab. 54:108-114.

25. Rapoport, B., F. S. Greenspan, S. Filetti, and M. Pepitone. 1984. Clinical experience with a human thyroid cell bioassay for thyroid-stimulating immunoglobulin. J. Clin. Endocrinol. Metab. 58:332-338.
26. Steiner, A. L., D. M. Kipnis, R. Utiger, and C. Parker. 1969. Radioimmunoassay for the measurement of adenosine $3^{\prime} 5^{\prime}$-cyclic phosphate. Proc. Natl. Acad. Sci. USA. 64:367-373.

27. Harper, J. F., and G. Brooker. 1975. Femtomole sensitive radioimmunoassay for cyclic AMP and cyclic GMP after $2^{\prime} 0$ acetylation by acetic anhydride in aqueous solution. J. Cyclic Nucleotide Res. 1: 207-218.

28. Rapoport, B., and Adams, R. J. 1978. Bioassay of TSH using dog thyroid cells in monolayer culture. Metabolism. 27:1732-1742.

29. Dufau, M. L., I. Z. Beitins, J. W. McArthur, and K. J. Catt. 1976. Effects of luteinizing hormone releasing hormone (LHRH) upon bioactive and immunoreactive serum LH levels in normal subjects. $J$. Clin. Endocrinol. Metab. 43:658-667.

30. Lucky, A. W., R. W. Rebar, R. L. Rosenfield, N. Roche-Bender, and J. Helke. 1979. Reduction of the potency of luteinizing hormone by estrogen. $N$. Engl. J. Med. 300:1034-1036.

31. Larsen, P. R. 1982. Thyroid-pituitary interaction. N. Engl. J. Med. 306:23-32.

32. Shupnik, M. A., W. W. Chin, J. F. Habener, and E. C. Ridgway. 1985. Transcriptional regulation of the thyrotropin subunit genes by thyroid hormone. J. Biol. Chem. 260:2900-2903.

33. Gurr, J. A., and I. A. Kourides. 1985. Thyroid hormone regulation of thyrotropin $\alpha$ - and $\beta$-subunit gene transcription. DNA (NY). 4:301307.

34. Belchetz, P. E., G. Gredley, D. Bird, and R. L. Himsworth. 1977. Regulation of thyrotropin secretion by negative feedback of triiodothyronine on the hypothalamus. J. Endocrinol. 76:439-448.

35. Joshi, L. R., and B. D. Weintraub. 1983. Naturally occurring forms of thyrotropin with low bioactivity and altered carbohydrate content act as competitive antagonists to more bioactive forms. Endocrinology. 113:2145-2154.

36. Amr, S., M. Menezes-Ferreira, Y. Shimohigashi, H. C. Chen, B. Nisula, and B. D. Weintraub. 1985. Activities of deglycosylated thyrotropin at the thyroid membrane receptor-adenylate cyclase system. $J$. Endocrinol. Invest. 8:537-541.

37. Taylor, T., and B. D. Weintraub. 1985. Differential regulation of thyrotropin subunit apoprotein and carbohydrate biosynthesis by thyroid hormone. Endocrinology. 116:1535-1542.

38. Ronin, C., B. S. Stannard, and B. D. Weintraub. 1985. Differential processing and regulation of thyroid-stimulating hormone subunit carbohydrate chains in thyrotropic tumors and in normal and hypothyroid pituitaries. Biochemistry. 24:5626-5631.

39. Wide, L., and M. Wide. 1984. Higher plasma disappearance rate in the mouse for pituitary follicle-stimulating hormone of young women compared to that of men and elderly women. J. Clin. Endocrinol. Metab. $58: 426-429$.

40. Constant, R. B., and B. D. Weintraub. 1986. Differences in the metabolic clearance of pituitary and serum thyrotropin (TSH) derived from euthyroid and hypothyroid rats: effects of chemical deglycosylation of pituitar. TSH. Endocrinology. 119:2720-2727.

41. Menezes-Ferreira, M. M., P. Petrick, and B. D. Weintraub. 1986. Regulation of thyrotropin bioactivity by thyrotropin releasing hormone and thyroid hormone. Endocrinology. 118:2125-2130.

42. Taylor, T., and B. D. Weintraub. 1985. Thyrotropin (TSH)-releasing hormone regulation of TSH subunit biosynthesis and glycosylation in normal and hypothyroid rat pituitaries. Endocrinology. 116:19681976.

43. Burstein, S., E. Schaff-Blass, J. Blass, and R. L. Rosenfield. 1985. The changing ratio of bioactive to immunoreactive luteinizing hormone (LH) through puberty principally reflects changing $\mathrm{LH}$ radioimmunoassay dose-response characteristics. J. Clin. Endocrinol. Metab. 61:508-513. 